\title{
THE DEVELOPMENT OF GIS EDUCATIONAL RESOURCES SHARING AMONG CENTRAL TAIWAN UNIVERSITIES
}

\author{
Tien-Yin Chou, Mei-Ling Yeh, Yu-Chen Lai \\ jimmy@gis.tw, milly@gis.tw, daphne@gis.tw \\ GIS Research Center, Feng Chia University \\ 100 Wen-Hwa Rd., Taichung, Taiwan 407
}

KEY WORDS: e-learning platform, collaboration, educational resources sharing

\begin{abstract}
:
Using GIS in the classroom enhance students' computer skills and explore the range of knowledge. The paper highlights GIS integration on e-learning platform and introduces a variety of abundant educational resources. This research project will demonstrate tools for e-learning environment and delivers some case studies for learning interaction from Central Taiwan Universities.

Feng Chia University (FCU) obtained a remarkable academic project subsidized by Ministry of Education and developed elearning platform for excellence in teaching/learning programs among Central Taiwan's universities. The aim of the project is to integrate the educational resources of 13 universities in central Taiwan. FCU is serving as the hub of Center University. To overcome the problem of distance, e-platforms have been established to create experiences with collaboration enhanced learning. The e-platforms provide coordination of web service access among the educational community and deliver GIS educational resources. Most of GIS related courses cover the development of GIS, principles of cartography, spatial data analysis and overlaying, terrain analysis, buffer analysis, 3D GIS application, Remote Sensing, GPS technology, and WebGIS, MobileGIS, ArcGIS manipulation. In each GIS case study, students have been taught to know geographic meaning, collect spatial data and then use ArcGIS software to analyze spatial data. On one of e-Learning platforms provide lesson plans and presentation slides. Students can learn Arc GIS online. As they analyze spatial data, they can connect to GIS hub to get data they need including satellite images, aerial photos, and vector data.

Moreover, e-learning platforms provide solutions and resources. Different levels of image scales have been integrated into the systems. Multi-scale spatial development and analyses in Central Taiwan integrate academic research resources among CTTLRC partners. Thus, establish decision-making support mechanism in teaching and learning. Accelerate communication, cooperation and sharing among academic units
\end{abstract}

\section{INTRODUCATION}

\subsection{Overview}

Computer based GIS have been used since the late 1960s in Canada for land management system. In the recent years, As Information technologies prevails, GIS becomes popular among government units, academic units and private companies. GIS is a system designed to capture, store, manipulate, analyse, manage, and present all types of geographically referenced data GIS applications are tools that allow users to create interactive queries, analyse spatial information, edit data, maps, and present the results of all these operations. GIS applications have been used in different fields such as land management, urban planning, ecology and transportation and so on.

\subsection{The Development of GIS}

Most users learn GIS by stand-alone system at the early ear. As Internet prevails, the advanced Web-GIS platforms have been developed demonstrating Web 2.0 features and sharing mechanism.

\subsection{GIS Education for Universities}

From 2005 to 2010, FCU received the highest amounts in reward subsidies from the Ministry of Education (MOE) for excellence in teaching/learning program among Taiwan's universities. There are 6 Resource Centres among general universities in Taiwan. The Teaching Learning Resource
Centre project is an initiative to create collaboration between universities with the following mission.

- To share the resource between universities

- To establish the collaborative mechanisms

- To build the e-platform

- To integrate the social resource

FCU is serving as the hub of Centre University. The aim of CTTLRC Project (Central Taiwan Teaching and Learning Resource Centre) is to integrate the educational resources of 13 universities in central Taiwan. To overcome the problem of distance, e-platforms have been established. The e-platforms provide coordination of web service access among the educational community.

GIS Research Centre, FCU, is very active to promote GIS education program and train students' capabilities of spatial thinking and data analyses. Meanwhile, the centre helped FCU establish collaborative e-learning platform of GIS education and provide different levels of image scales, such as aerial photos, satellite images, UAV(unmanned aerial vehicle) images. E-learning platform integrate GIS educational resources and deliver value-added services among the Central Taiwan Universities.

\section{LITERATURE REVIEW}

\subsection{GIS Education}

Research shows that geographic information systems (GIS) have a great potential to increase geography education (White 
and Simms 1993; Baker and Bednarz 2003). GIS can promote a student's ability to understand spatial concepts, facilitate spatial thinking, and learn class subject matter (Donaldson 2001; Audet and Paris 1997; Baker and White 2003). These capabilities can help students understand spatial analysis concepts such as distance, location, proximity, or distinct boundaries (Kerski 2001). The concept of spatial patterns prompts students to learn advanced spatial analysis methods; which include the integration of diverse spatial information, spatial-temporal context, spatially explicit modelling, and place-based organization

\subsection{Public Participation GIS}

Public Participation Geographic Information Systems (PPGIS) was born, as a term, in 1996 at the meetings of the National Centre for Geographic Information and Analysis (NCGIA).(Sieber 2006) Public Participation GIS (PPGIS) focuses on the use of GIS by non-experts and occasional users. These aspects require that the systems used within PPGIS are accessible and easy to use. The Web has greatly improved connectivity and data access, which, in turn, promote collaboration among geographic and non-geographic information providers.(Wong and Chou, 2001) In this context, the Web increases awareness of integrating non-geographic information such as local knowledge into GIS operations.

\subsection{Project-based Learning}

Project-based learning (PBL) is a "comprehensive instructional approach to engage students in sustained, cooperative investigation"(Bransford \& Stein, 1993) that can be used in all disciplines. John Thomas (2000) explains that project-based learning requires "complex tasks, based on challenging questions or problems, that involve students in design, problem-solving, decision making, or investigative activities; give students the opportunity to work relatively autonomously over extended periods of time; and culminate in realistic products or presentations.

\section{THE DEVELOPMENT OF GIS EDUCATION}

GIS is the subject based on theories and best practices. Feng Chia University has developed GIS education like figure 1. At the early stage, GIS in the classroom focused on stand-alone system like ArcInfo learning spatial analyses. The widespread use of the Internet has given people access to GIS information on a level never experienced before. GIS Research Centre, FCU would integrate research achievements into Blue Maps for teaching programs and then created GIS education program and developed Web-GIS platform called e-Design. The eDesign platform provides GIS online learning courses and spatial data warehouse. Teachers at Construction \& Development colleges have planned the theme subjects with the teaching method of the project practice and learn how to solve problems with GIS concepts and techniques on the eDesign platform. Most teachers adopt project based learning to lead students learn GIS techniques through projects and cultivate capabilities of solving problems.

The e-Design GIS education platform has been successfully promoted to FCU. The experiences of GIS education sharing on e-platform have been transferred to the partner universities among Central Taiwan. Then, the centre developed Regional Planning and Education Resources Website based on Google Earth to share GIS educational resources among Central Taiwan Universities. This platform incorporates ideas about
Web 2.0 and PPGIS concepts to share educational resources online like spatial data and project reports.

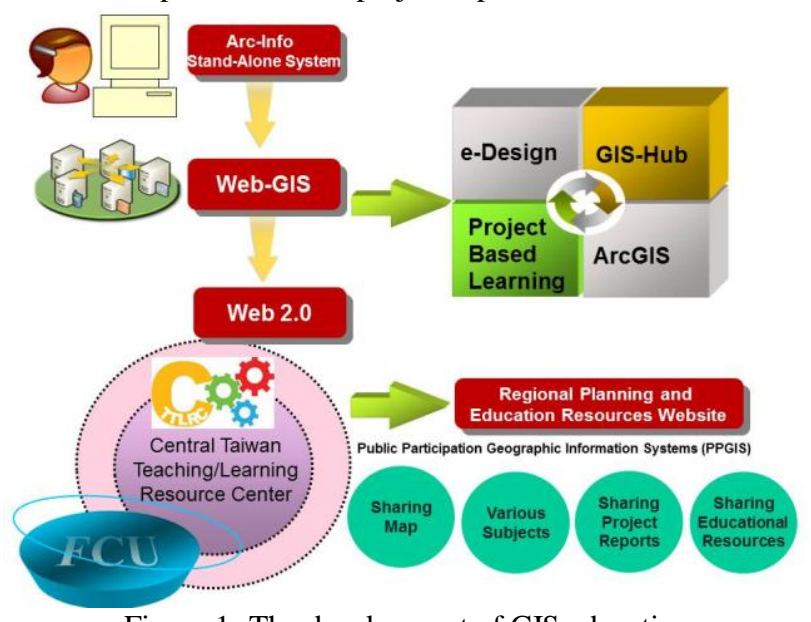

Figure 1 The development of GIS education

\subsection{Develop Web-based GIS Education platform}

\subsubsection{E-Desing learning platform}

In the recent year, Feng Chia University (FCU) obtained a remarkable academic project subsidized by Ministry of Education and developed e-learning platform-“E-Design". EDesign, the core of the e-Learning platform, is designed for all departments under the college of construction and development to manage courses, teaching materials, and records of students' works. The website of E-Design, which focuses on teaching, learning, and knowledge sharing, includes three main sections, such as, instructors, students, and online resources.

Instructors will prepare teaching materials for a variety of courses including handout, presentation slides, and references and then display them on web as teaching in classes. After a class, students can browse information on web for reviewing or downloading. See the Figure 2 (1) indicates various courses; (2) shows course content for reviewing; (3) provides the quick access to GIS hub when analyze spatial data during classes.

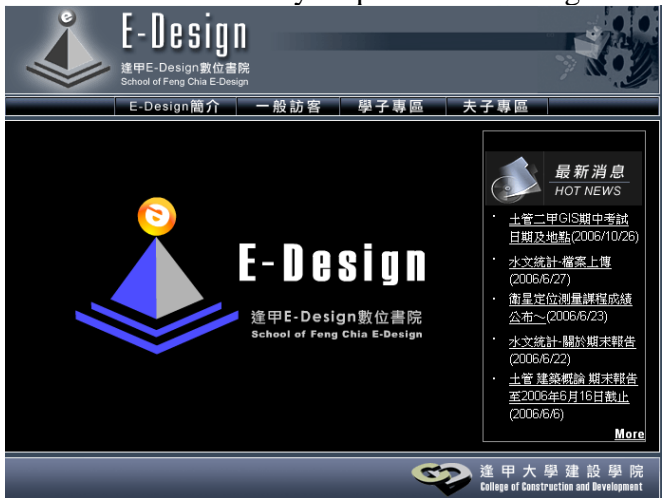

Figure 2 GIS Education Platform-“e-Design”

3.1.2 Learning Arc GIS Online

Students will learn ArcGIS on e-Design platform. This platform offers some online courses to teach ArcGIS step by step. Students can follow video instruction to learn how to use ArcGIS.

\subsubsection{Integrate GIS Data Warehouse}

Instructors or students can set up queries to search spatial layers they need in e-Design platform which links to the search system of GIS hub. (Figure 3) All spatial layers can be previewed to have the better understanding. (Figure 4) Moreover, according to topics assigned by instructors in a 
variety of courses, students can use ArcGIS to show analyzing results. Instructors will select some of best spatial analyses displayed on e-Design platform or saved for the other researches in the future. On the other hand, GIS hub inspires students to gradually create innovative ideas on spatial analyses and raise students' capabilities of spatial design.

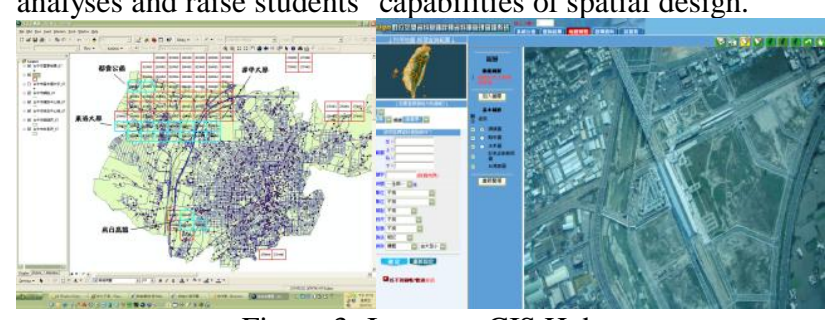

Figure 3 Integrate GIS Hub

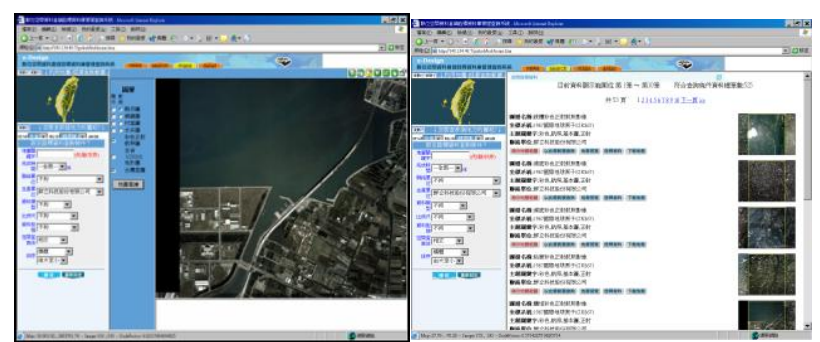

Figure 4 GIS Hub for preview the search result of spatial data

\subsection{Project Based Learning}

Most of universities adopt traditional teaching methods and deliver "one-way communication" in the lecture classrooms or experiment courses. This research paper mentions project based learning for learners to solve problems and for instructors to play the role in leading spatial thinking.

One effective method of exploring and thinking about the world with GIS, rather than simply learning how to manipulate the software, is to base all projects on a carefully chosen problem. This method- Problem Based Learning (PBL) encourages teachers and students to apply concepts and skills to investigate a real-world issue.

\subsubsection{Problem solving}

Students choose topics related to a variety of fields and learn to use GIS to conduct their inquiry, like land management, public services, regional development, fleet motoring, disaster mitigation and prevention. When students complete their research, they prepare their written explanations of their finding including GIS analyses. Teachers will need to assist students in structuring their results and summary.

3.2.2 Investigation

Providing access to adequate resources that support in-depth investigations is an extremely important role of the teacher. Make the problem related to the real world. Specify the questions that students must define and answer during their investigation. Moreover, teach students to interpret topographic maps, images of remote sensing, vector data, so that students can search those spatial data they need.

3.2.3 Spatial data analyses

The teacher instructed students to manipulate software, such as map overlap, coordinate, digital image processing, network analyses, interpolation and so on. In some cases, students learn to use GIS software in displaying different layers of data or linking databases.

3.2.4 Visualize spatial data

In addition to spatial analyses, the centre integrated 3D simulation and remote sensing. Use DEM and site model development to design 3D simulation, students can learn environment transition, debris flow disaster demonstration and community development.(Figure 5)

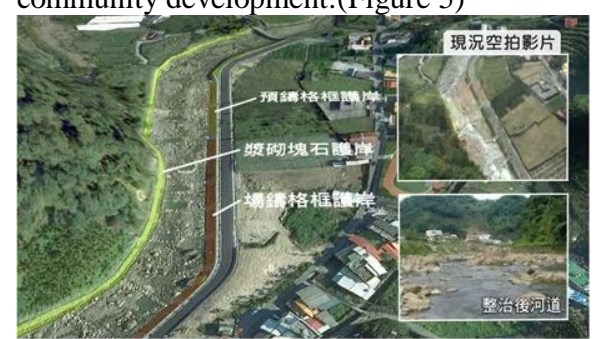

Figure 5 3D Simulation

\subsection{Regional Planning and Education Resources Website}

Feng Chia University made alliance with other universities in the central Taiwan. The centre develops the platform for sharing education resources and student services.

This is an interactive platform not only for students but also for faculty of governments. On the one hand, student can resolve the spatial data for their projects and home-works. On the other hand, faculties can make policy discussion or resource planning on this platform. The platform is called for "Regional Planning and Education Resources Website." (Figure 6)

\subsubsection{Connect to Open-GIS}

The website integrated Open-GIS platform "Google Earth". Google Earth provides all users with satellite images and spatial data. Meanwhile, Google Earth also offered KML services so users can customize their maps, and 3D models or specific information.

3.3.2 E-learning Platform to provide solutions and resources This platform provides solutions and resources. Different levels of image scales have been integrated into the system. For instance, aerial photos, satellite images, UAV images are included. Each of the subjects may link to different sources of image data. This will be facilitated for the user to use various subjects to handle their own projects.

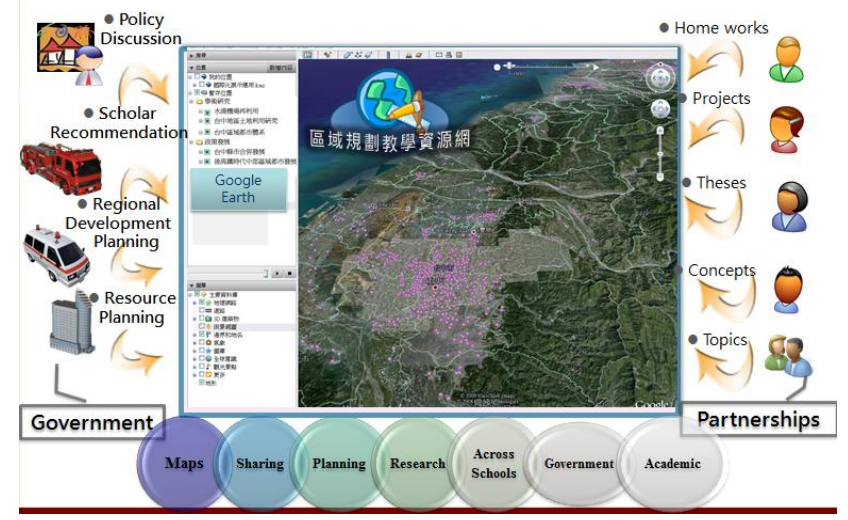

Figure 6 Regional Planning and Education Resources Website 3.3.3 Integrate GIS data warehouse

GIS data warehouse stores abundant spatial data including satellite images, aerial photos, and vector data. It provides users with access to spatial data, includes data search, browse, map overlay, and downloads functions. The data warehouse will intensify GIS information values. In GIS Data Warehouse, instructors or students can set up queries to search spatial layers they need. All spatial layers can be previewed and overlaid to have the better understanding. Students can get their spatial data for their team projects, search spatial data according to topics and then analyse data to create the specific theme maps. 


\subsubsection{Resources Sharing}

All instructors or students can share the spatial information of thesis or dissertation on this platform. Here are two examples. The first example is that students used spatial techniques to approach the site selection of firefly habitat. The teacher instructed students to use one of ArcGIS functions - inversedistance weighting (IDW) and then created a variety of theme maps based on different living criteria, such as temperature, humidity, and altitude. After that, adopt overlay to select appropriate site for firefly habitat. This project would be substantial for researches of firefly conservation and promotion.(Figure 7 and 8)

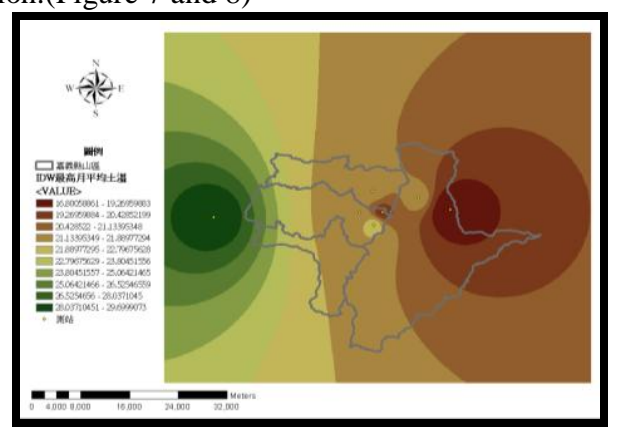

Figure 7develop theme maps based on spatial data

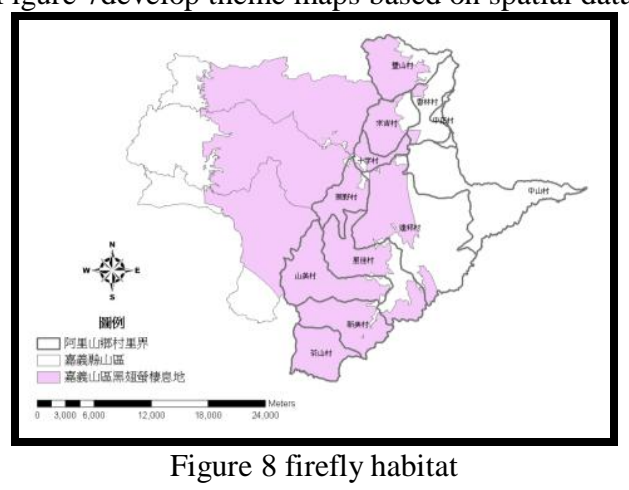

The other example is to demonstrate industry cluster analysis in Taichung city and county. Different industry zones are distributed spatially on the map. Students need different layers of map, metadata, social and economic data. That information comes from different government agencies. This website is served as a platform for students to collect and download data.

\subsubsection{Beneficial effect}

This website is going to increase a variety of abundant education resources, because it integrates academic research resources among CTTLRC partners. FCU develop multi-scale spatial development and analyses in Taiwan, so government units or academic research units can make spatial simulation for decision-making support in regional development. Meanwhile, the platform establishes decision-making support mechanism in teaching and learning and accelerates communication between government units and academic units.

\section{CONCLUSION}

GIS education gradually changed from stand-alone system to the Web-GIS platform. As Internet prevails, Web-GIS learning platform has been adopted to share educational resources. Students learn GIS techniques by project based learning. It is an effective way to cultivate different perspectives of time and space. It also teaches them a valuable perspective, how to think geographically. PBL-GIS connects students with their world and teaches them the spatial problem solving. Students' projects share on e-learning platform and demonstrate Web 2.0 features.

The experiences of GIS education sharing on e-platform have been transferred to the partner universities among Central Taiwan. The e-learning platform incorporates ideas about Web 2.0 and PPGIS concepts to share resources online. FCU is serving as the hub of Centre University. The aim of CTTLRC Project (Central Taiwan Teaching and Learning Resource Centre) is to integrate the educational resources of 13 universities in central Taiwan. After developing e-learning platform and integrating GIS data warehouse, all partner universities can share spatial data, explore a variety of spatial subjects, adopt different scale of images, and feedback the project results. Thus, educational resources become abundant. CTTLRC built e-learning platform and establish the collaborative mechanisms to share educational resources among universities.

\section{REFERENCE}

Audet, R. H., and J. Paris. 1997. GIS implementation model for schools: assessing the critical concerns. Journal of Geography 96 (6):293-300.

Baker, T. R., and S. H. White. 2003. The effects of G.I.S. on students' attitudes, self-efficacy, and achievement in middle school science classrooms. Journal of Geography 102 (6):243254.

Baker, T. R., and S. W. Bednarz. 2003. Lessons learned from reviewing research in GIS education. Journal of Geography 102 (6):231-233.

Bransford, J. D., and B. S. Stein. 1993. The IDEAL problem solver (2nd ed.) New York: Freeman.

Donaldson, D. P. 2001. With a little help from our friends: implementing geographic information systems (GIS) in K-12 schools. Social Education 65 (3):147-150.

Kerski, J. J. 2001. A national assessment of GIS in American high schools. International Research in Geographic and Environmental Education 10 (1):72-84.

Sieber, R. 2006. Public Participation and Geographic Information Systems: A Literature Review and Framework. Annals of the American Association of Geographers, 96/3:491507

Thomas, J. (2000). A Review of the Research on Project-Based Learning. The Autodesk Foundation.

White, K. L., and M. Simms. 1993. Geographic information systems as an educational tool. Journal of Geography 92 (2):80-85.

Wong, S. and Chua, Y.L. 2001. Data Intermediation and Beyond: Issues for Web-Based PPGIS. Cartographica: The International Journal for Geographic Information and Geovisualization 38(3): 63-80 